\title{
Sarcopenia in Hepatocellular Carcinoma: Pathogenesis and Management
}

\author{
Paolo Gallo ${ }^{a}$ Marianna Silletta ${ }^{b}$ Antonio De Vincentis ${ }^{c}$ Federica Lo Prinzi ${ }^{b}$ \\ Francesca Terracciani $^{\mathrm{a}}$ Giuseppina Di Fazio $^{\mathrm{b}}$ Valentina Flagiello ${ }^{\mathrm{a}}$

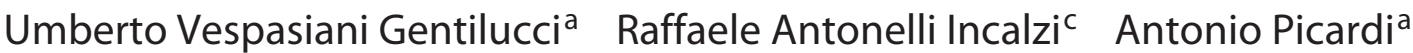

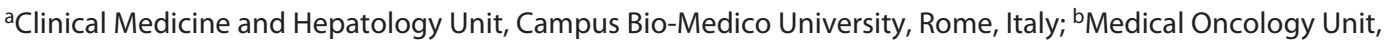 \\ Campus Bio-Medico University, Rome, Italy; 'Internal Medicine Unit, Campus Bio-Medico University, Rome, Italy
}

\section{Keywords}

Sarcopenia $\cdot$ Hepatocellular carcinoma $\cdot$ Muscle mass .

Nutrition $\cdot$ Branched-chain amino acids

\begin{abstract}
Background: Sarcopenia is almost constantly observed in patients with cirrhosis and hepatocellular carcinoma (HCC). Summary: Chronic liver disease represents a unique pathophysiological scenario in which sarcopenia develops and all factors involved in the pathogenesis should be taken into account for an appropriate management of the disease. No properly designed intervention studies on this topic are available and, thus, no effective strategies have been developed for clinical practice. Apart from any targeted intervention, treatment, and optimization of liver disease is crucial. Key Messages: In patients with cirrhosis and HCC, nutritional support to maintain and restore nutrition status, a targeted use of branched-chain amino acids and a guided physical exercise, should all be an integral part of the multidimensional assessment and tailored interventions.
\end{abstract}

(c) 2021 S. Karger AG, Basel

karger@karger.com www.karger.com/che

(C) 2021 S. Karger AG, Basel

Karger"

\section{Introduction}

\section{Hepatocellular Carcinoma}

Liver cancer is the fourth most frequent cause of cancer-related death in the world and is associated with high rates of mortality [1]. Hepatocellular carcinoma (HCC) represents the principal form of primary liver cancer, and major risk factors for HCC include cirrhosis caused by chronic infection with the hepatitis $\mathrm{C}$ and hepatitis $\mathrm{B}$ viruses, heavy alcohol drinking, and above all in recent years, non-alcoholic fatty liver disease that is already the fastest growing cause of HCC in Western countries [2-4]. As most patients with HCC have underlying cirrhosis, a multidisciplinary evaluation including tumour stage, liver function, and performance status, as well as comorbidities, is essential in therapeutic decision-making [5].

Early diagnosis in patients with a well-preserved liver function is crucial to facilitate curative therapy. When patients are not suitable for surgery, transplantation or locoregional treatments, systemic therapy is the choice. The multikinase inhibitor sorafenib has been for long time the only systemic treatment available for advanced HCC. Recently, 
various trials have reported a clinical benefit and prolonged survival (more than 2 years) in advanced HCC for the tyrosine kinase inhibitors (TKIs) (lenvatinib, regorafenib, and cabozantinib), for an angiostatic antibody (ramucirumab) and for immune checkpoint inhibitors, alone or in combination (nivolumab, pembrolizumab, atezolizumab in combination with bevacizumab and ipilimumab in combination with nivolumab). Some of these drugs have been approved so far as first or second-line treatment by national agencies $[5,6]$. This new scenario has opened opportunities in the choice and sequential application of systemic treatments and has made even more important selection of patients and the shift to systemic treatment lines prior to the onset of critical hepatic dysfunction, when best supportive care becomes the only reasonable option.

From this perspective, the general assessment of patients becomes crucial and a multidisciplinary approach is essential. However, actual staging and prognostic systems do not include parameters assessing the functional and nutritional status notwithstanding these factors have already been associated with outcomes in patients with cancers [7].

In the last decade, research has focused its attention on the role of sarcopenia and frailty in chronic liver disease (CLD) as modifiable (if early identified) factors whose recognition and periodical assessment is critical because of strong association with morbidity, mortality, and quality of life [8-10]. Depending on the population evaluated, the prevalence of sarcopenia and frailty in cirrhotic liver disease is very high and estimated from 40 to $70 \%$ and $18-43 \%$ [11-14], respectively. Therefore, starting from these assumptions, the aim of this review is to describe the complex pathophysiology and the role of assessment and management of sarcopenia in patients with cirrhosis and HCC.

\section{Sarcopenia in CLD}

Sarcopenia is a very common complication observed in patients with cirrhosis $[11,12]$ and differently from geriatric literature [10], it is mainly diagnosed in the clinical setting using operational definitions based on low muscle mass. Various techniques have been applied to quantify muscle mass in this context and, to date, the most well-validated tools are the psoas and lumbar vertebral body cross-sectional imaging assessments by computed tomography or magnetic resonance imaging [15, 16]. Several studies have shown that total skeletal muscle index estimated at the level of L3 vertebra is the most accurate predictor of whole-body muscle mass [17-20].
Anyhow, while the North American collaboration cutoffs for the diagnosis of sarcopenia are the most widely used criteria (skeletal muscle index $<50 \mathrm{~cm}^{2} / \mathrm{m}^{2}$ in males $<39 \mathrm{~cm}^{2} / \mathrm{m}^{2}$ in females) [21], studies on the validation of computed tomography $\backslash$ magnetic resonance imaging in the overall population and on the application of other tools in the cirrhotic patients are still missing and needed (Table 1). Ultrasound evaluation is easy and readily available, but its use for the diagnosis of sarcopenia is still in promising steps. Bioimpedance analysis and dual-energy $\mathrm{X}$-ray absorptiometry are not always available, and accuracy among cirrhotic patients might suffer from the interference of ascites and fluid retention. Handgrip strength has been associated with adverse clinical outcomes in patients with end-stage liver disease [21] but it may not be accurate when normalized to body mass index in cirrhosis due to fluctuating body water content $[22,23]$.

Most studies on sarcopenia in CLD have been conducted in patients awaiting liver transplantation, where sarcopenia is associated with an increased risk of complications and negative outcomes [24, 25]. Extensive data (even if heterogeneous) support the prognostic role of sarcopenia even in patients with compensated or decompensated CLD outside the transplant setting [26]. Moreover, literature clearly shows that, regardless of liver function, sarcopenia is associated with the risk of complications (hepatic encephalopathy (HE), infection, and delirium.) [24, 27, 28], hospitalization [29], higher healthcare costs [29], and mortality in CLD [12, 30-32], and is correlated with negative outcomes and poor survival in patients with HCC [33]. Nowadays, sarcopenia is one of the several pathogenic mechanisms that have contributed to the worse prognosis and higher mortality of cirrhotic patients with severe COVID-19 infection [34].

On the one hand, it is well known the prognostic negative role of sarcopenia in all patients with various forms of cancer and its association with overall reduced survival [7]. On the other hand, it should be emphasized that in patients with HCC complicating cirrhosis, the pathophysiological substrate of sarcopenia is more complex, outlining a unique pathology setting whose identification and treatment in early stages becomes even more important.

\section{Physiopathology of Sarcopenia in Cirrhosis and Cancer}

In liver disease, sarcopenia is a multifactorial process whose mechanisms have not been extensively clarified since few preclinical and clinical studies have been devel- 
Table 1. Commonly used methods to assess sarcopenia in cirrhosis

\begin{tabular}{|c|c|c|}
\hline Methods & Pros & Cons and unmet needs \\
\hline CT scan SMI at the 3rd lumbar vertebrae & $\begin{array}{l}\text { Assessment of muscle quality and quantity } \\
\text { No interference from ascites } \\
\text { Well-validated as a predictor of mortality }\end{array}$ & $\begin{array}{l}\text { Expensive and with radiation exposure } \\
\text { No standardized cut-off in overall population and } \\
\text { cirrhotic patients }\end{array}$ \\
\hline $\begin{array}{l}\text { CT psoas muscle thickness adjusted for } \\
\text { height and psoas muscle area }\end{array}$ & $\begin{array}{l}\text { Assessment of muscle quality and quantity } \\
\text { No interference from ascites }\end{array}$ & $\begin{array}{l}\text { Less-validated as a predictor of mortality } \\
\text { Expensive and with radiation exposure } \\
\text { No standardized cut-off in overall population and } \\
\text { cirrhotic patients }\end{array}$ \\
\hline $\begin{array}{l}\text { DEXA appendicular and upper limb lean } \\
\text { mass-height adjusted }\end{array}$ & $\begin{array}{l}\text { Highly precise measure of lean mass } \\
\text { Validated in cirrhotic population } \\
\text { Low radiation exposure }\end{array}$ & $\begin{array}{l}\text { Interference of fluid retention } \\
\text { No data as a predictor of mortality }\end{array}$ \\
\hline $\mathrm{BIA}$ & Inexpensive, fast and without radiation exposure & $\begin{array}{l}\text { Interference of fluid retention and ascites } \\
\text { No data as a predictor of mortality } \\
\text { No well validation in cirrhotic patients }\end{array}$ \\
\hline $\begin{array}{l}\text { Ultrasound (Quadriceps muscle diameter } \\
\text { and muscle psoas index) }\end{array}$ & Inexpensive, fast and without radiation exposure & $\begin{array}{l}\text { Inter-and intra-operator variability } \\
\text { No data as a predictor of mortality } \\
\text { No validation in large cohorts and clinical practice }\end{array}$ \\
\hline HGS & $\begin{array}{l}\text { Inexpensive, simple and reproducible } \\
\text { Assessment of muscle function (not mass) }\end{array}$ & $\begin{array}{l}\text { Affected by hepatic complications (i.e., } \\
\text { encephalopathy) } \\
\text { No validation in large cohorts and clinical practice }\end{array}$ \\
\hline
\end{tabular}

DEXA, dual-energy X-ray absorptiometry; BIA, bioelectrical impedance; CT, computed tomography; SMI, skeletal muscle index; HGS, handgrip strength.

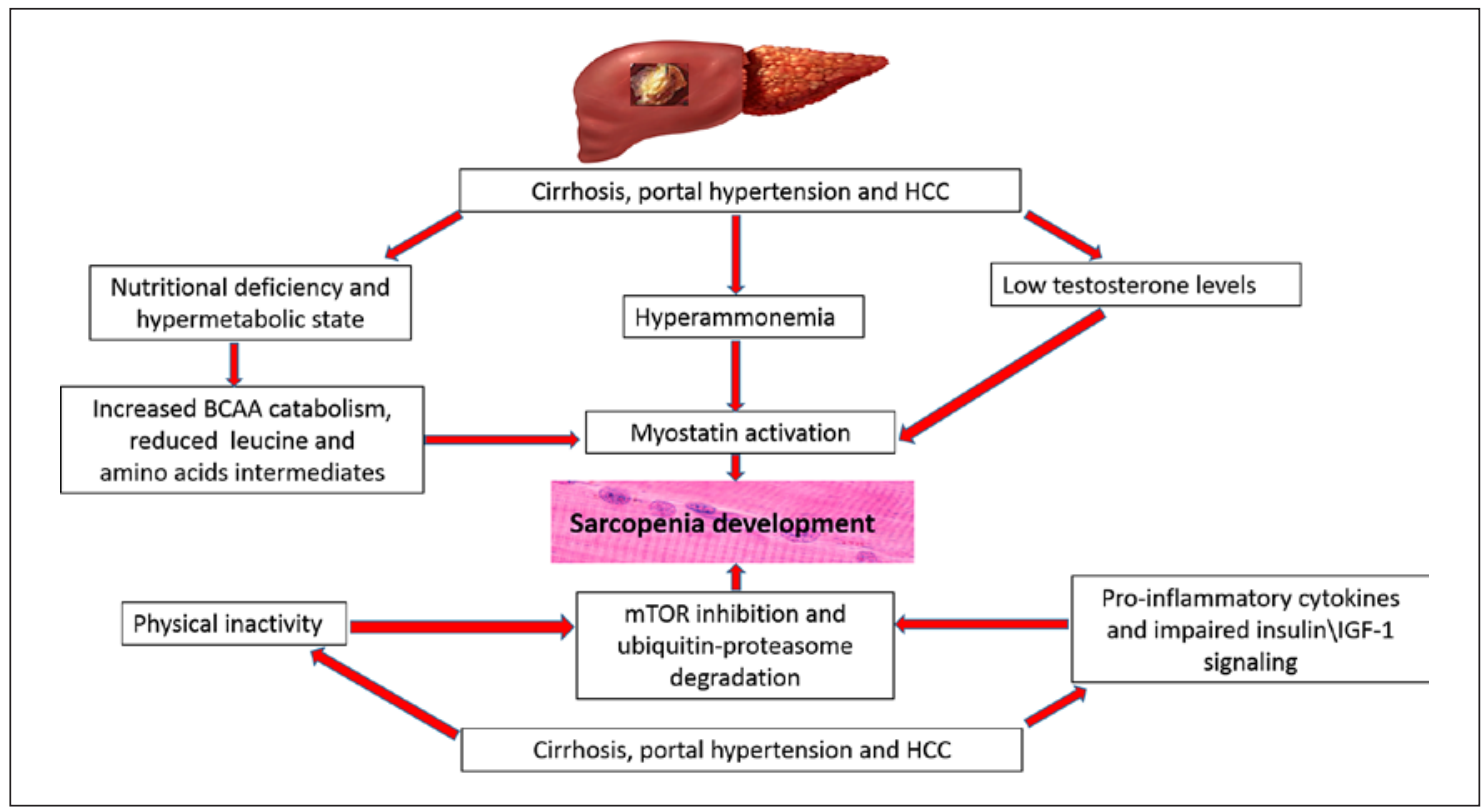

Fig. 1. Principal physiopathological mechanisms of sarcopenia in patients with liver cirrhosis and HCC.

oped in humans [35]. Malabsorption, hyperammonemia, metabolism alteration, hormonal defects, and overall increased muscle loss are all considered potential contributors to disease development (Fig. 1). In addition, sarcopenia can cause an overestimation of renal function based on serum creatinine, both because of a concomitant reduced hepatic production of creatinine and of a low rate of creatinine conversion due to skeletal muscle mass loss $[36,37]$. 


\section{Malabsorption and Metabolism Alterations}

Inadequate nutrients intake is frequently observed in cirrhotic patients [38], generally due to several causes: altered taste induced by vitamin deficiency and dietetic restrictions [39]; increased abdominal pressure caused by ascites [39]; impaired gastrointestinal motility associated to portal hypertension [40]; altered bile flow in the gut that contributes to fat malabsorption and is associated with bacterial overgrowth and inflammation [41].

Furthermore, cirrhosis is a condition of accelerated starvation and hypermetabolic state that increases the demand for proteins and calories [42]. Within a short period of fasting ( $10 \mathrm{~h}$ in patients of cirrhosis are equivalent to 3 days of starvation in a healthy subject [43]), because of the limited hepatic glycogen stores, there is an excessive consumption of body fats and proteins used for gluconeogenesis [44] with the degradation of skeletal muscle proteins to make gluconeogenic substrates available. Moreover, hepatic gluconeogenesis is enhanced in patients with cancer as HCC, probably to provide the tumour cells with de novo synthesized glucose [45]. The overall increased utilization of amino acids results in reduced levels of plasma branchedchain amino acids (BCAAs) and, as a consequence, in reduced supply of this preferred energy source to the skeletal muscles with further muscle degradation [46-48].

\section{Hormonal Defects and Increase Muscle Loss}

Male patients with cirrhosis have low testosterone levels [49]. Testosterone improves protein synthesis and muscle mass activating mammalian target of rapamycin through insulin-like growth factor- 1 [50] and is responsible of the downregulation of myostatin whose activation is involved in the pathogenesis of muscle wasting in sarcopenia or cachexia associated with different diseases $[51,52]$. Indeed, elevated myostatin levels may have a significant role in increasing muscle loss since this myokine negatively regulates the proliferation and the differentiation of satellite cells [53]. In addition, proteostasis in cirrhosis is unbalanced in favour of proteolysis [54] as a result, among others, of the chronic inflammation with elevated levels of pro-inflammatory cytokines [55].

\section{Hyperammonemia}

Hyperammonemia plays a relevant role in cirrhosis as part of the liver-muscle axis contributing to the development of sarcopenia. Ammonia disposal is impaired in cirrhosis due to hepatocyte dysfunction and portosystemic shunting [56]. In this context, muscle plays a relevant compensatory role in removing ammonia by transforming glutamate into glutamine through the presence of the enzyme glutamine synthase [57], and therefore, sarcopenia hastens the development of HE [58]. Moreover, hyperammonaemia mediates the activation of p65-nuclear factor kappa $B$ that is associated with an increased expression of myostatin [59]. At the same time, it impairs the tricarboxylic acid cycle ultimately entailing a reduction of protein synthesis [35]. Lastly, an altered flux of the essential amino acid L-leucine in the muscle plays another important role in this physiopathological process [60].

\section{Cancer and Sarcopenia}

In addition to the mechanisms involved in the development of sarcopenia in CLD, patients with HCC develop a sarcopenia secondary to tumour burden that derives, in a more peculiar way, from the systemic cytokine-mediated inflammation observed in cancer [61]. Muscle loss is further exacerbated by some age-related features (physical inactivity, malnutrition, and hormonal alterations) typically observed in patients with cancer [62]. Sarcopenic patients have a poorer tolerance to cancer treatments and a greater incidence of complications (infection, chemotherapy toxicity, and perioperative problems) is observed [63]. Furthermore, patients with cancer develop a syndrome of cachexia that is another multifactorial disease similar to sarcopenia but characterized not only by muscle loss but also by total body weight loss [64]. There is a considerable overlap in the development of cachexia and sarcopenia and these conditions may coexist. Generally, cancer cachexia is caused by a complex interplay between anorexia, increased protein catabolism, systemic inflammation, and increased resting state energy expenditure with inflammation playing a more relevant role, respect to sarcopenia, in the development of cachexia [65].

\section{HCC Treatment Settings and Sarcopenia}

\section{Surgery and Liver Transplant}

The role of sarcopenia in the development and prognosis of patients undergoing hepatic resection for HCC has been evaluated in many studies conducted in the last decade. It has been clearly shown that sarcopenia is correlated with impaired liver function and with a worse prognosis after liver surgery respect to overall and recurrence-free survival [66-68]. Moreover, sarcopenia has been correlated with the stage and histological features of tumours (stage, presence of satellite nodules, and dedifferentiation in liver histology) $[67,68]$, and the risk of recurrence after liver resection was found to be associated 
to sarcopenic obesity $[69,70]$ that is significantly linked with poorer overall survival in all patients with cancer [71]. In addition, sarcopenic patients undergoing hepatic resection have shown a functional smaller liver volume compared to the non-sarcopenic ones and they are at increased risk of complications, longer hospitalization, negative outcomes, and liver failure $[72,73]$.

These data are even more robust in the transplantation setting where most of the studies on sarcopenia in liver disease have been developed [12, 25, 48]. These studies confirm the correlation between sarcopenia and survival among liver transplantation candidates [12] to such an extent that modification of model for end-stage liver disease (MELD)-score, to include sarcopenia, has been proposed and has shown to perform better than MELD in predicting mortality in cirrhotic patients awaiting transplantation (mainly in patients with low MELD scores) [12]. Finally, sarcopenia was found to be associated with worse post-operative outcomes (complications, hospital stay, and overall survival) even after liver transplantation [74].

\section{Local and Locoregional Treatments}

Local and locoregional treatments are the recommended strategies for a large proportion of subjects with HCC (BCLC stage 0-A-B) [75]. Few studies have focused their attention on the prognostic role of sarcopenia in these settings [76-81]. Overall, most studies [78, 79] showed that pre-treatment low muscle mass is an independent risk factor for reduced survival. When evaluated, the reduction of muscle mass over time after locoregional treatments was always associated with poorer outcomes $[78,79]$.

In any case, many methodological drawbacks currently hamper firm conclusions on this topic and should be adequately taken into account when facing with often heterogeneous results. Firstly, many different districts and measures of sarcopenia were applied, and in 2 studies, patients with both primary and secondary liver tumours were included $[77,80]$. This clearly makes available data poorly comparable, and significantly limits the consistency of reported results. Secondly, the only studies evaluating the impact of sarcopenia on treatment response and post-procedural morbidity found inconsistent associations [77, 80], suggesting the prognostic impact of sarcopenia on locoregional procedure to depend more deeply upon its role over the general clinical conditions of cirrhotic patients with HCC, rather than on its role on the efficacy of the procedure. Finally, most of the data are derived from retrospective studies including a relatively small number of patients.

\section{Systemic Treatment}

A comprehensive assessment is one of the major determinants of choice in cancer patient candidates to systemic treatment. In addition to the clinical performance status scales (such as Karnofsky and ECOG performance scale), sarcopenia represents an objective parameter to better select and follow patients when systemic treatment is the chosen strategy. Several retrospective studies demonstrated a correlation between sarcopenia and worse outcomes in cancer patients treated with antineoplastic drugs. A recent meta-analysis [82] correlates sarcopenia with mortality analysing different cancers during systemic treatment. In a cohort of patients affected by primary liver cancers, mortality was more than doubled and pre-treatment sarcopenia reduced the efficacy of anticancer therapy in terms of response rate inducing lower drug tolerability and higher toxicity $[83,84]$. Moreover, systemic treatments exacerbate muscle loss through the intrinsic mechanisms of action of some drugs and through various side effects promoting muscle mass depletion [85].

\section{Sarcopenia and TKIs}

In an interesting systematic review and meta-analysis assessing the prognostic role of muscle mass loss in patients treated with TKIs in different cancer types, a strong association was reported between sarcopenia and poor overall survival, as well as dose-limiting toxicities, in patient affected by HCC and treated with sorafenib. In literature, the majority of retrospective studies aiming to analyse the effect of sarcopenia in HCC patients under systemic treatment concerns patients undergoing sorafenib treatment, as a result of a longer clinical availability.

With sorafenib administration, Mir et al. [86] showed a higher prevalence of dose-limiting toxicity in sarcopenic patients that, interestingly, were more frequently treated with an initial dose of $200 \mathrm{mg}$ b.i.d. as a clinical choice of the physician. In other 2 retrospective studies $[87,88]$, sarcopenia was reported as an independent prognostic factor for overall survival and for treatment interruption. Moreover, sarcopenia was shown to be a good predictor of drug toxicity in patients treated with lenvatinib and was correlated with lenvatinib tolerability $[89,90]$.

Lastly, as mentioned above, there is also evidence that systemic drugs could favour sarcopenia through direct mechanisms since, for example, TKI downstream signalling includes alterations of phosphatidylinositol-3-kinase/AKT-mammalian target of rapamycin pathway, that is physiologically implied in muscle protein synthesis [91] whose dysregulation induced by drugs could favour further muscle loss [92]. 
Fig. 2. Proposed strategy to treat sarcopenia in patients with liver cirrhosis and HCC.

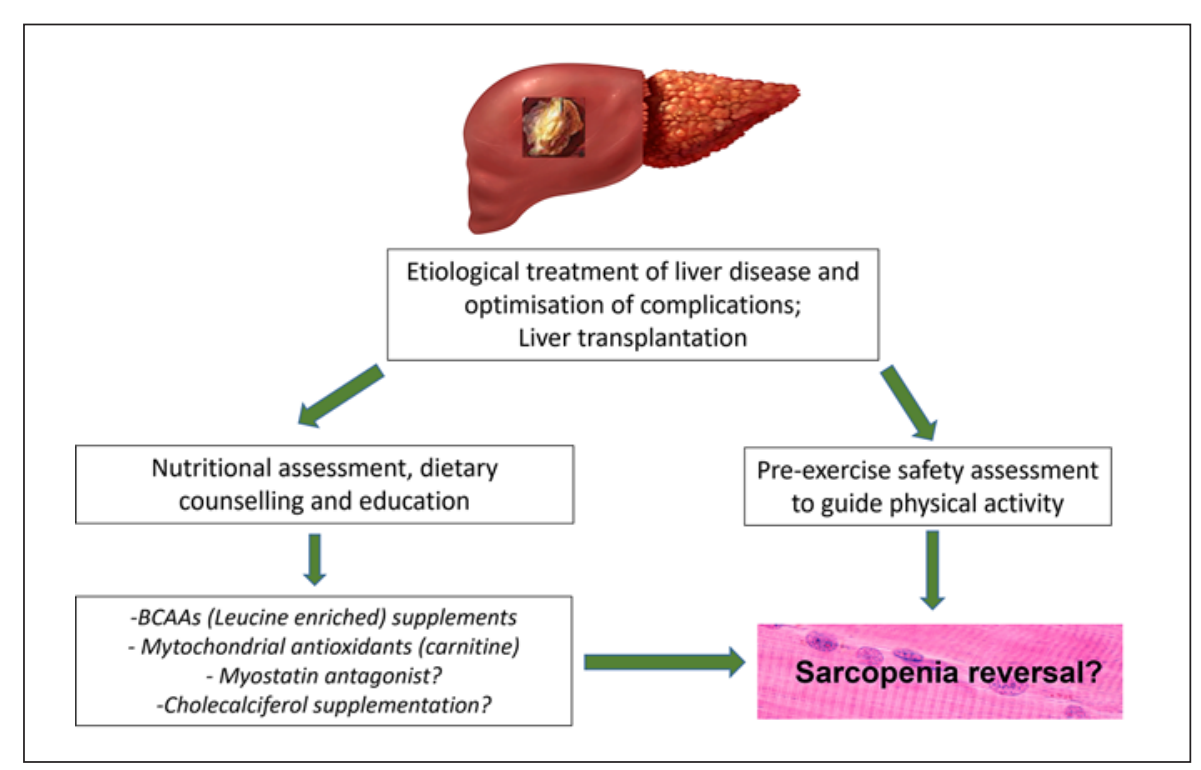

\section{Sarcopenia and Immunotherapy}

Immunotherapy is becoming the frontline standard of care in patients affected by advanced HCC. The pathogenic mechanism of sarcopenia in this setting may be explained by the interplay between skeletal muscle and the immune system. The same cytokines implicated in sarcopenia, such as TGF- $\beta$ and IL- 6 , have also been cited as mediators of T-cell exhaustion. Therefore, the decreased muscle mass may have a direct link to immune dysregulation, resistance to immune checkpoint inhibitors, and poorer outcomes in patients with cancer treated with these agents [93]. Several studies have assessed the relationship between sarcopenia and immunotherapy in cancer, especially in breast and lung cancer, and have shown a lower objective disease control and a shorter progression-free survival in sarcopenic patients [94].

Instead, only 2 studies have explored the correlation between sarcopenia and immunotherapy in patients with cirrhosis and HCC. In these studies, sarcopenia has been associated with a lower survival independently from confounders with median overall survival of 5 versus 14.3 months in sarcopenic versus non-sarcopenic patients [95, 96].

\section{Management of Sarcopenia in Cirrhosis and HCC}

No effective strategies have been developed or routinely used in clinical practice to treat sarcopenia in cirrhotic patients with HCC. Outside of any specific interventions, optimal management of underlying liver disease and complications is primarily required. Nutrition and physical exercise represent the mainstay of current available strategies and are supported by several clinical studies (Fig. 2).

\section{Nutrition and Supplementation}

Dietary counselling should be a priority for all patients with cirrhosis and HCC. In any case, available meta-analyses have not been able to demonstrate an impact of nutritional supplementation on mortality [97] probably for the very short length of the studies. In a recent randomized-controlled trial (RCT), a 6-month intervention of guided dietary intake and monthly dietician visits in patients with decompensated cirrhosis and minimal HE, has shown an increase of muscle mass and strength and an improvement in minimal HE in the intervention group $[98,99]$. In clinical practice, a key nutritional strategy includes small frequent meals with a late-night snack containing carbohydrates or proteins to reduce fat and protein catabolism, and improve nitrogen balance [100]. Even more important is the guidance of a dietician in the setting of sarcopenic obesity and decompensated cirrhosis where, at the same time, protein intake should be maintained and weight loss should be achieved [101].

While the role of an adequate protein intake has been clearly demonstrated, data supporting the use of BCAA are less consistent. Several studies have demonstrated that BCAAs improve the quality of life and reduce the incidence of HE $[102,103]$, but the largest meta-analyses of studies conducted in patients with encephalopathy have shown no impact on mortality [104]. In any case, guide- 
lines recommend intake of BCAAs at the dose of $0.25 \mathrm{gl}$ kg\day [99, 105]. Among BCAAs, leucine has demonstrated the greatest significant clinical benefit particularly through its active metabolite beta-hydroxy-beta-methylbutyrate $[106,107]$ that exerts anti-catabolic effects on skeletal muscles [107]. Oral leucine supplementation at a dose of 10 glday, combined with physical activity, has been associated with an improvement of muscle mass and quality of life in cirrhotic patients after 12 weeks of supplementation [108]. A long-term administration of BCAA (12 grlday) for 2 years was associated with reduced levels of blood ammonia, reduced incidence of decompensation and better serum nutritional status and quality of life in cirrhotic patients [103]; however, no data about the impact on muscle mass and function were collected in this study.

In addition, relevant data derive from a RCT performed in patients with advanced solid cancers by Deutz et al. [109] in which the experimental group received a medical food containing $40 \mathrm{~g}$ protein, based on casein and whey protein and enriched with 10\% free leucine compared to the control group receiving conventional food based on casein protein alone ( $24 \mathrm{~g}$ ). Experimental supplementation induced a higher muscle protein synthesis overcoming the anabolic resistance to conventional medical food, observed in patients with advanced cancer. The interesting data on hydroxy-beta-methylbutyrate have been confirmed in patients with metastatic solid cancers whose supplementation with this nutrient was associated with increased lean body weight after 6 months of treatment with respect to controls [110].

Mitochondrial targeted antioxidants are another potential therapy to treat oxidative stress and restore protein synthesis [111]. Carnitine plays an important role in this metabolism and L-carnitine supplementation has demonstrated to prevent skeletal muscle mass loss in patients with cirrhosis after 1,000 mglday administration for more than 6 months [112] and seems to have a dose-dependent effectiveness $[113,114]$. Anyhow, not enough evidence has been developed in this context to recommend carnitine.

As regards to the role of cholecalciferol, while observational studies and mechanistic experiments clearly support a biological link between low vitamin $\mathrm{D}$ levels and the decline in muscle mass, strength and physical performance, and RCTs conducted to investigate the effect of oral vitamin supplementation to prevent or treat sarcopenia yielded conflicting results [115]. Indeed, while the association of cholecalciferol deficiency with CLD and mortality is known [116], its role in the treatment of sar- copenia in cirrhosis has only marginally been evaluated. Recently, a small pilot RCT has been conducted in patients with decompensated cirrhosis $(28 \%$ of patients with a history of HCC) that routinely received BCAA preparations, showing that vitamin $\mathrm{D}$ supplementation significantly increases muscle volume and grip strength after 12 months of treatment [117]. The small sample and the absence of a control arm without BCAA supplementation limit the results of the study but simultaneously confirm the suggested effective role of vitamin D supplementation in these patients. Therefore, currently available evidence remains limited in this field and vitamin D supplementation certainly maintains a key role only in the sustainment of an optimal skeletal health in oncological patients [118].

Lastly, the role of follistatin, a myostatin antagonist, is of particular interest in patients with cirrhosis and HCC, but even if some studies have already demonstrated a role for this molecule in stimulation of muscle mass and strength in preclinical studies [119] and an association between follistatin/myostatin levels and survival in patients with HCC [120], no clinical evidence have been developed. Moreover, for the heterogeneity and the small sample of the studies, no conclusive data and evidence have been developed for vitamin $\mathrm{C}$, eicosapentaenoic acid, and docosahexaenoic acid supplementations [121].

\section{Hormonal Treatment}

Starting from the pathophysiological assumption of the reduced levels of testosterone in advanced liver disease, hormonal treatment has been evaluated in cirrhotic patients showing a significant improvement of muscle mass and bone mineral treatment [122]. Even though these promising results, many evidences suggest a role of testosterone in the development of HCC $[123,124]$ and therefore, it does not represent auseful tool in sarcopenia treatment in CLD and HCC.

\section{Physical Exercise}

Many recent studies have focused their attention on the benefits of physical exercise in patients with cirrhosis $[125,126]$. The role of structured physical activity is confirmed by studies developed in patients with many types of cancer. For instance, progressive resistance exercises fort 12 weeks improved lean body mass of $4.2 \%$ in patients with head and neck squamous cell cancer [127]. Most of the available data in liver disease derive from cirrhotic compensated patients, but no evidence has been produced on the impact on reversal of sarcopenia. In any case, it seems noticeable that, if possible, physical exercise 
should be recommended to all patients with cirrhosis and with HCC in the early stages to prevent further loss of muscle mass [128]. Exercise has shown to improve muscle mass and strength, peak exercise capacity, fatigue, and hepatic venous pressure $[129,130]$. Both walking $30 \mathrm{~min}$ three times per week and resistance exercise have shown to improve muscle mass in cirrhosis [131]. Studies conducted in patients with HCC subjected to locoregional treatment (mainly trans-arterial chemoembolization) have shown that exercise, alone or with supplementation with BCAAs, is associated with a lesser decrease of muscle mass during hospital stay or after 50 days from treatment with respect to controls [132, 133]. Finally, the role of physical exercise in patients awaiting LT has been only marginally evaluated [134] but no randomized clinical trials have been developed to assess its beneficial role on hospitalization and mortality. A preliminary care and safety assessment should be paid to identify patients with high risk of varices or HE (to optimize treatment and prophylaxis), to assess cardiopulmonary function and contextualize the best choices in patients under systemic active oncological treatment.

\section{Conclusion}

The evidence of such an important prognostic role of sarcopenia in CLD and HCC makes the clinician's interventions even more important since sarcopenia recognition and proactive treatment may significantly improve patients' outcomes. Particularly, in the context of HCC, sarcopenia evaluation requires an all-encompassing ap- proach that takes into account not only cancer but primarily underlying CLD. Besides, future prospective studies with larger sample size and appropriate end points are urgently needed to provide more robust evidence about the prognostic role of sarcopenia in this specific setting and to verify the efficacy of nutritional, pharmacological, and non-pharmacological interventions in reversing sarcopenia.

\section{Acknowledgements}

The final version of the manuscript has been seen and approved by all the authors. We deny any financial, personal, or other relationships with drug manufacturers that could lead to a conflict of interest.

\section{Conflict of Interest Statement}

The authors have no conflicts of interest to declare.

\section{Funding Sources}

The authors received no financial support for the research, authorship, and/or publication of this article.

\section{Author Contributions}

P.G. conceived the study and wrote the manuscript; M.S., A.D.V., F.L.P., F.T., G.D.F., and V.F. wrote the manuscript; U.V.G. and A.P. helped in drafting and revising the manuscript; R.A.I. revised the manuscript for important intellectual contents.

\section{References}

1 Bray F, Ferlay J, Soerjomataram I, Siegel RL, Torre LA, Jemal A. Global cancer statistics 2018: GLOBOCAN estimates of incidence and mortality worldwide for 36 cancers in 185 countries. CA Cancer J Clin. 2018 Nov;68(6): 394-424.

2 Yang JD, Hainaut P, Gores GJ, Amadou A, Plymoth A, Roberts LR. A global view of hepatocellular carcinoma: trends, risk, prevention and management. Nat Rev Gastroenterol Hepatol. 2019 Oct;16(10):589-604.

3 Huang DQ, El-Serag HB, Loomba R. Global epidemiology of NAFLD-related HCC: trends, predictions, risk factors and prevention. Nat Rev Gastroenterol Hepatol. 2021 Apr;18(4):223-38.

4 Pennisi G, Celsa C, Giammanco A, Spatola F, Petta S. The burden of hepatocellular carci- noma in non-alcoholic fatty liver disease: screening issue and future perspectives. Int J Mol Sci. 2019 Nov;20(22):5613.

5 Cohen GS, Black M. Multidisciplinary management of hepatocellular carcinoma: a model for therapy. J Multidiscip Healthc. 2013 May;6:189.

6 Bruix J, Chan SL, Galle PR, Rimassa L, Sangro B. Systemic treatment of hepatocellular carcinoma: an EASL position paper. J Hepatol. 2021 Oct;75(4):960-74.

7 Shachar SS, Williams GR, Muss HB, Nishijima TF. Prognostic value of sarcopenia in adults with solid tumours: a meta-analysis and systematic review. Eur J Cancer. 2016 Apr;57:58-67.

8 Vitale A, Farinati F, Noaro G, Burra P, Pawlik TM, Bucci L, et al. Restaging patients with hepatocellular carcinoma before additional treatment decisions: a Multicenter Cohort Study. Hepatology. 2018 Oct;68(4) 1232-44.

9 Chen LK, Woo J, Assantachai P, Auyeung TW, Chou MY, Iijima K, et al. Asian Working Group for sarcopenia: 2019 consensus update on sarcopenia diagnosis and treatment. J Am Med Dir Assoc. 2020 Mar;21(3): 300-7.e2.

10 Cruz-Jentoft AJ, Bahat G, Bauer J, Boirie Y, Bruyère $O$, Cederholm $T$, et al. Sarcopenia: revised European consensus on definition and diagnosis. Age Ageing. 2019 Jan;48(1):16-31.

11 Kim HY, Jang JW. Sarcopenia in the prognosis of cirrhosis: going beyond the MELD score. World J Gastroenterol. 2015;21(25): 7637. 
12 Montano-Loza AJ, Duarte-Rojo A, MezaJunco J, Baracos VE, Sawyer MB, Pang JXQ, et al. Inclusion of sarcopenia within MELD (MELD-Sarcopenia) and the prediction of mortality in patients with cirrhosis. Clin Transl Gastroenterol. 2015 Jul;6(7):e102.

13 Tandon P, Tangri N, Thomas L, Zenith L, Shaikh T, Carbonneau M, et al. A rapid bedside screen to predict unplanned hospitalization and death in outpatients with cirrhosis: a prospective evaluation of the clinical frailty scale. Am J Gastroenterol. 2016 Dec;111(12): 1759-67.

14 Cron DC, Friedman JF, Winder GS, Thelen AE, Derck JE, Fakhoury JW, et al. Depression and frailty in patients with end-stage liver disease referred for transplant evaluation. Am J Transplant. 2016 Jun;16(6):1805-11.

15 Tandon P, Mourtzakis M, Low G, Zenith L, Ney M, Carbonneau M, et al. Comparing the variability between measurements for sarcopenia using magnetic resonance imaging and computed tomography imaging. Am J Transpl. 2016;16(9):2766-7.

16 Praktiknjo M, Book M, Luetkens J, Pohlmann A, Meyer C, Thomas D, et al. Fat-free muscle mass in magnetic resonance imaging predicts acute-on-chronic liver failure and survival in decompensated cirrhosis. Hepatology. 2018; 67(3):1014-26.

17 Shen W, Punyanitya M, Wang Z, Gallagher D, St.-Onge MP, Albu J, et al. Total body skeletal muscle and adipose tissue volumes: estimation from a single abdominal cross-sectional image. J Appl Physiol. 2004 Dec;97(6):23338.

18 Su H, Ruan J, Chen T, Lin E, Shi L. CT-assessed sarcopenia is a predictive factor for both long-term and short-term outcomes in gastrointestinal oncology patients: a systematic review and meta-analysis. Cancer Imaging. 2019 Dec;19(1):82.

19 Hamaguchi Y, Kaido T, Okumura S, Fujimoto Y, Ogawa K, Mori A, et al. Impact of quality as well as quantity of skeletal muscle on outcomes after liver transplantation: impact of IMAC on liver transplantation. Liver Transpl. 2014 Nov;20(11):1413-9.

20 Kim TY, Kim MY, Sohn JH, Kim SM, Ryu JA, Lim S, et al. Sarcopenia as a useful predictor for long-term mortality in cirrhotic patients with ascites. J Korean Med Sci. 2014;29(9):1253.

21 Carey EJ, Lai JC, Sonnenday C, Tapper EB, Tandon P, Duarte-Rojo A, et al. A North American Expert Opinion Statement on sarcopenia in liver transplantation. Hepatology. 2019 Nov;70(5):1816-29.

22 Guglielmi FW, Contento F, Laddaga L, Panella C, Francavilla A. Bioelectric impedance analysis: experience with male patients with cirrhosis. Hepatology. 1991 May;13(5):892-5.

23 Zillikens MC, van den Berg JW, Wilson JH, Swart GR. Whole-body and segmental bioelectrical-impedance analysis in patients with cirrhosis of the liver: changes after treatment of ascites. Am J Clin Nutr. 1992 Mar;55(3): $621-5$.
24 Bhanji RA, Moctezuma-Velazquez C, Duarte-Rojo A, Ebadi M, Ghosh S, Rose C, et al. Myosteatosis and sarcopenia are associated with hepatic encephalopathy in patients with cirrhosis. Hepatol Int. 2018 Jul;12(4):377-86.

25 Montano-Loza AJ, Meza-Junco J, Baracos VE, Prado CMM, Ma M, Meeberg G, et al. Severe muscle depletion predicts postoperative length of stay but is not associated with survival after liver transplantation: sarcopenia after liver transplantation. Liver Transpl. 2014 Jun;20(6):640-8.

26 Ebadi M, Montano-Loza AJ. Clinical relevance of skeletal muscle abnormalities in patients with cirrhosis. Dig Liver Dis. 2019 Nov; 51(11):1493-9.

27 Masuda T, Shirabe K, Ikegami T, Harimoto N, Yoshizumi T, Soejima Y, et al. Sarcopenia is a prognostic factor in living donor liver transplantation: sarcopenia is a prognostic factor in LDLT. Liver Transpl. 2014 Apr; 20(4):401-7.

28 Zucchelli A, Manzoni F, Morandi A, Di Santo S, Rossi E, Valsecchi MG, et al. The association between low skeletal muscle mass and delirium: results from the nationwide multicentre Italian Delirium Day 2017. Aging Clin Exp Res. 2021 Aug.

29 Norman K, Kirchner H, Lochs H, Pirlich M. Malnutrition affects quality of life in gastroenterology patients. World J Gastroenterol. 2006;12(21):3380.

30 DiMartini A, Cruz RJ, Dew MA, Myaskovsky L, Goodpaster B, Fox K, et al. Muscle mass predicts outcomes following liver transplantation: muscle mass predicts outcomes after transplantation. Liver Transpl. 2013 Nov; 19(11):1172-80.

31 Durand F, Buyse S, Francoz C, Laouénan C, Bruno O, Belghiti J, et al. Prognostic value of muscle atrophy in cirrhosis using psoas muscle thickness on computed tomography. J Hepatol. 2014 Jun;60(6):1151-7.

32 Kaido T, Ogawa K, Fujimoto Y, Ogura Y, Hata K, Ito T, et al. Impact of sarcopenia on survival in patients undergoing living donor liver transplantation: impact of sarcopenia on liver transplantation. Am J Transpl. 2013 Jun; 13(6):1549-56.

33 Ha Y, Kim D, Han S, Chon YE, Lee YB, Kim $\mathrm{MN}$, et al. Sarcopenia predicts prognosis in patients with newly diagnosed hepatocellular carcinoma, independent of tumor stage and liver function. Cancer Res Treat. 2018 Jul; 50(3):843-51.

34 Kara M, Ata AM, Özçakar L. Sarcopenic obesity is the real problem in COVID-19! Eur J Intern Med. 2021 Nov;93:103-4

35 Dasarathy S, Merli M. Sarcopenia from mechanism to diagnosis and treatment in liver disease. J Hepatol. 2016 Dec;65(6):1232-44.

36 Yoshida S, Suda G, Ohara M, Fu Q, Yang Z, Hosoda $S$, et al. Frequency and characteristics of overestimated renal function in Japanese patients with chronic liver disease and its relation to sarcopenia. Nutrients. 2021 Jul;13(7): 2415 .
37 Yoo JJ, Kim SG, Kim YS, Lee B, Lee MH, Jeong SW, et al. Estimation of renal function in patients with liver cirrhosis: impact of muscle mass and sex. J Hepatol. 2019 May;70(5): 847-54.

38 Hayashi F, Matsumoto Y, Momoki C, Yuikawa M, Okada G, Hamakawa E, et al. Physical inactivity and insufficient dietary intake are associated with the frequency of sarcopenia in patients with compensated viral liver cirrhosis: sarcopenia in compensated liver cirrhosis. Hepatol Res. 2013 Dec;43(12): 1264-75.

39 Madden AM, Bradbury W, Morgan MY Taste perception in cirrhosis: its relationship to circulating micronutrients and food preferences. Hepatology. 1997 Jul;26(1):40-8.

40 Romiti A, Merli M, Martorano M, Parrilli G, Martino F, Riggio O, et al. Malabsorption and nutritional abnormalities in patients with liver cirrhosis. Ital J Gastroenterol. 1990 Jun; 22(3):118-23.

41 Ridlon JM, Kang DJ, Hylemon PB, Bajaj JS. Bile acids and the gut microbiome. Curr Opin Gastroenterol. 2014 May;30(3):332-8.

42 Morrison WL, Bouchier IA, Gibson JN, Rennie MJ. Skeletal muscle and whole-body protein turnover in cirrhosis. Clin Sci. 1990 Jun; 78(6):613-9.

43 Chang WK, Chao YC, Tang HS, Lang HF, Hsu CT. Effects of extra-carbohydrate supplementation in the late evening on energy expenditure and substrate oxidation in patients with liver cirrhosis. JPEN J Parenter Enteral Nutr. 1997 Mar-Apr;21(2):96-9.

44 Lundsgaard AM, Kiens B. Gender differences in skeletal muscle substrate metabolism - molecular mechanisms and insulin sensitivity. Front Endocrinol. 2014 Nov;5:195.

45 Vaitheesvaran B, Xu J, Yee J, Lu QY, Go VL, Xiao GG, et al. The Warburg effect: a balance of flux analysis. Metabolomics. 2015 Aug; 11(4):787-96

46 Petersen KF, Krssak M, Navarro V, Chandramouli V, Hundal R, Schumann WC, et al. Contributions of net hepatic glycogenolysis and gluconeogenesis to glucose production in cirrhosis. Am J Physiol. 1999 Mar;276(3): E529-35.

47 Geer EB, Shen W. Gender differences in insulin resistance, body composition, and energy balance. Gend Med. 2009 Jan;6 Suppl 1:6075.

48 van Vugt JLA, Alferink LJM, Buettner S, Gaspersz MP, Bot D, Darwish Murad S, et al. A model including sarcopenia surpasses the MELD score in predicting waiting list mortality in cirrhotic liver transplant candidates: a competing risk analysis in a national cohort. J Hepatol. 2018 Apr;68(4): 707-14.

49 Handelsman DJ, Strasser S, McDonald JA, Conway AJ, McCaughan GW. Hypothalamic-pituitary-testicular function in end-stage non-alcoholic liver disease before and after liver transplantation. Clin Endocrinol. 1995 Sep;43(3):331-7. 
50 Grossmann M, Hoermann R, Gani L, Chan I, Cheung A, Gow PJ, et al. Low testosterone levels as an independent predictor of mortality in men with chronic liver disease. Clin Endocrinol. 2012 Aug;77(2):323-8.

51 Orr R, Fiatarone Singh M. The anabolic androgenic steroid oxandrolone in the treatment of wasting and catabolic disorders: review of efficacy and safety. Drugs. 2004;64(7):725-50.

52 Elkina Y, von Haehling S, Anker SD, Springer J. The role of myostatin in muscle wasting: an overview. J Cachexia Sarcopenia Muscle. 2011 Sep;2(3):143-51.

53 Krell RW, Kaul DR, Martin AR, Englesbe MJ, Sonnenday CJ, Cai S, et al. Association between sarcopenia and the risk of serious infection among adults undergoing liver transplantation. Liver Transpl. 2013 Dec;19(12): 1396-402.

54 Cohen S, Nathan JA, Goldberg AL. Muscle wasting in disease: molecular mechanisms and promising therapies. Nat Rev Drug Discov. 2015 Jan;14(1):58-74.

55 Beyer I, Mets T, Bautmans I. Chronic lowgrade inflammation and age-related sarcopenia. Curr Opin Clin Nutr Metab Care. 2012 Jan;15(1):12-22.

56 Shangraw RE, Jahoor F. Effect of liver disease and transplantation on urea synthesis in humans: relationship to acid-base status. Am J Physiol. 1999 May;276(5):G1145-52.

57 Jindal A, Jagdish RK. Sarcopenia: ammonia metabolism and hepatic encephalopathy. Clin Mol Hepatol. 2019 Sep;25(3):270-9.

58 Bémeur C, Rose CF. Hepatic encephalopathy, sarcopenia, and frailty. In: Tandon P, Montano-Loza AJ, editors. Frailty and sarcopenia in cirrhosis. Cham: Springer International Publishing; 2020. p. 247-63.

59 Anand AC. Nutrition and muscle in cirrhosis. J Clin Exp Hepatol. 2017 Dec;7(4):340-57.

60 Davuluri G, Krokowski D, Guan BJ, Kumar A, Thapaliya S, Singh D, et al. Metabolic adaptation of skeletal muscle to hyperammonemia drives the beneficial effects of l-leucine in cirrhosis. J Hepatol. 2016 Nov;65(5):929-37.

61 Roubenoff R, Parise H, Payette HA, Abad LW, D'Agostino R, Jacques PF, et al. Cytokines, insulin-like growth factor 1, sarcopenia, and mortality in very old community-dwelling men and women: the Framingham Heart Study. Am J Med. 2003 Oct;115(6):429-35.

62 Dhillon RJ, Hasni S. Pathogenesis and management of sarcopenia. Clin Geriatr Med. 2017 Feb;33(1):17-26.

63 Kazemi-Bajestani SM, Mazurak VC, Baracos V. Computed tomography-defined muscle and fat wasting are associated with cancer clinical outcomes. Semin Cell Dev Biol. 2016 Jun;54:2-10.

64 Dhanapal R, Saraswathi T, Govind RN. Cancer cachexia. J Oral Maxillofac Pathol. 2011; 15(3):257.

65 Rolland Y, Van Kan GA, Gillette-Guyonnet S, Vellas B. Cachexia versus sarcopenia. Curr Opin Clin Nutr Metab Care. 2011 Jan;14(1): $15-21$.
66 Harimoto N, Shirabe K, Yamashita YI, Ikegami T, Yoshizumi T, Soejima Y, et al. Sarcopenia as a predictor of prognosis in patients following hepatectomy for hepatocellular carcinoma. Br J Surg. 2013 Sep;100(11):1523-30.

67 Voron T, Tselikas L, Pietrasz D, Pigneur F, Laurent A, Compagnon P, et al. Sarcopenia impacts on short- and long-term results of hepatectomy for hepatocellular carcinoma. Ann Surg. 2015 Jun;261(6):1173-83.

68 Takagi K, Yagi T, Yoshida R, Shinoura S, Umeda Y, Nobuoka D, et al. Sarcopenia and American Society of anesthesiologists physical status in the assessment of outcomes of hepatocellular carcinoma patients undergoing hepatectomy. Acta Med Okayama. 2016 Oct [cited 2021 Nov 16];70(5):363-70.

69 Yabusaki N, Fujii T, Yamada S, Suzuki K, Sugimoto $\mathrm{H}$, Kanda M, et al. Adverse impact of low skeletal muscle index on the prognosis of hepatocellular carcinoma after hepatic resection. Int J Surg. 2016 Jun;30:136-42.

70 Kobayashi A, Kaido T, Hamaguchi Y, Okumura S, Shirai H, Yao S, et al. Impact of sarcopenic obesity on outcomes in patients undergoing hepatectomy for hepatocellular carcinoma. Ann Surg. 2019 May;269(5):924-31.

71 Mintziras I, Miligkos M, Wächter S, Manoharan J, Maurer E, Bartsch DK. Sarcopenia and sarcopenic obesity are significantly associated with poorer overall survival in patients with pancreatic cancer: systematic review and meta-analysis. Int J Surg. 2018 Nov;59:19-26.

72 Dello SAWG, Lodewick TM, van Dam RM, Reisinger KW, van den Broek MAJ, von Meyenfeldt MF, et al. Sarcopenia negatively affects preoperative total functional liver volume in patients undergoing liver resection. HPB. 2013 Mar;15(3):165-9.

73 Otsuji H, Yokoyama Y, Ebata T, Igami T, Sugawara G, Mizuno T, et al. Preoperative sarcopenia negatively impacts postoperative outcomes following major hepatectomy with extrahepatic bile duct resection. World J Surg. 2015 Jun;39(6): 1494-500.

74 van Vugt JL, Levolger S, de Bruin RW, van Rosmalen J, Metselaar HJ, IJzermans JN. Systematic review and meta-analysis of the impact of computed tomography-assessed skeletal muscle mass on outcome in patients awaiting or undergoing liver transplantation. Am J Transplant. 2016 Aug;16(8):2277-92.

75 Galle PR, Forner A, Llovet JM, Mazzaferro V, Piscaglia F, Raoul JL, et al. EASL Clinical Practice Guidelines: management of hepatocellular carcinoma. J Hepatol. 2018 Jul;69(1): 182-236.

76 Yuri Y, Nishikawa H, Enomoto H, Ishii A, Iwata Y, Miyamoto Y, et al. Implication of psoas muscle index on survival for hepatocellular carcinoma undergoing radiofrequency ablation therapy. J Cancer. 2017;8(9):150716.

77 Loosen SH, Schulze-Hagen M, Bruners P, Tacke F, Trautwein C, Kuhl C, et al. Sarcopenia is a negative prognostic factor in patients undergoing transarterial chemoembolization
(TACE) for hepatic malignancies. Cancers. 2019 Oct;11(10):1503.

78 Kobayashi T, Kawai H, Nakano O, Abe S, Kamimura H, Sakamaki A, et al. Rapidly declining skeletal muscle mass predicts poor prognosis of hepatocellular carcinoma treated with transcatheter intra-arterial therapies. BMC Cancer. 2018 Dec;18(1):756.

79 Fujita M, Takahashi A, Hayashi M, Okai K, Abe K, Ohira H. Skeletal muscle volume loss during transarterial chemoembolization predicts poor prognosis in patients with hepatocellular carcinoma. Hepatol Res. 2019 Jul; 49(7):778-86.

80 Dodson RM, Firoozmand A, Hyder O, Tacher $\mathrm{V}$, Cosgrove DP, Bhagat N, et al. Impact of sarcopenia on outcomes following intra-arterial therapy of hepatic malignancies. J Gastrointest Surg. 2013 Dec;17(12):2123-32.

81 Faron A, Sprinkart AM, Pieper CC, Kuetting DLR, Fimmers R, Block W, et al. Yttrium-90 radioembolization for hepatocellular carcinoma: outcome prediction with MRI derived fat-free muscle area. Eur J Radiol. 2020 Apr; 125:108889.

82 Au PCM, Li HL, Lee GKY, Li GHY, Chan M, Cheung BMY, et al. Sarcopenia and mortality in cancer: a meta-analysis. Osteoporos Sarcopenia. 2021 Mar;7:S28-33.

83 Davis MP, Panikkar R. Sarcopenia associated with chemotherapy and targeted agents for cancer therapy. Ann Palliat Med. 2019 Jan; $8(1): 86-101$.

84 Susanto B, Hariyanto TI, Kurniawan A. The impact of sarcopenia on chemotherapy toxicity and survival rate among pancreatic cancer patients who underwent chemotherapy: a systematic review and meta-analysis. Ann Oncol. 2020 Nov;31:S1312.

85 Kodera Y. More than 6 months of postoperative adjuvant chemotherapy results in loss of skeletal muscle: a challenge to the current standard of care. Gastric Cancer. 2015 Apr; 18(2):203-4

86 Mir O, Coriat R, Blanchet B, Durand JP, Boudou-Rouquette P, Michels J, et al. Sarcopenia predicts early dose-limiting toxicities and pharmacokinetics of sorafenib in patients with hepatocellular carcinoma. PLoS One. 2012 May;7(5):e37563.

87 Nishikawa H, Nishijima N, Enomoto H, Sakamoto A, Nasu A, Komekado H, et al. Prognostic significance of sarcopenia in patients with hepatocellular carcinoma undergoing lenvletherapy. Oncol Lett. 2017 Aug;14(2):1637-47.

88 Antonelli G, Gigante E, Iavarone M, Begini P, Sangiovanni A, Iannicelli E, et al. Sarcopenia is associated with reduced survival in patients with advanced hepatocellular carcinoma undergoing sorafenib treatment. United European Gastroenterol J. 2018 Aug;6(7):1039-48.

89 Hiraoka A, Kumada T, Kariyama K, Tada T, Tani J, Fukunishi S, et al. Clinical importance of muscle volume in lenvatinib treatment for hepatocellular carcinoma: analysis adjusted with inverse probability weighting. J Gastroenterol Hepatol. 2021 Jul;36(7):1812-9. 
90 Uojima H, Chuma M, Tanaka Y, Hidaka H, Nakazawa T, Iwabuchi S, et al. Skeletal muscle mass influences tolerability and prognosis in hepatocellular carcinoma patients treated with lenvatinib. Liver Cancer. 2020; 9(2):193-206.

91 Edinger AL, Thompson CB. Akt maintains cell size and survival by increasing mTORdependent nutrient uptake. Mol Biol Cell. 2002 Jul;13(7):2276-88

92 Huemer F, Schlintl V, Hecht S, Hackl H, Melchardt T, Rinnerthaler G, et al. Regorafenib is associated with increased skeletal muscle loss compared to TAS-102 in metastatic colorectal cancer. Clin Colorectal Cancer. 2019 Jun;18(2):159-66.e3.

93 Bilen MA, Martini DJ, Liu Y, Shabto JM, Brown JT, Williams M, et al. Combined effect of sarcopenia and systemic inflammation on survival in patients with advanced stage cancer treated with immunotherapy. Oncologist. 2020 Mar;25(3):e528-35.

94 Nishioka N, Uchino J, Hirai S, Katayama Y, Yoshimura A, Okura N, et al. Association of sarcopenia with and efficacy of anti-PD-1/ PD-L1 therapy in non-small-cell lung cancer. JCM. 2019 Apr;8(4):450.

95 Akce M, Liu Y, Zakka K, Martini DJ, Draper A, Alese OB, et al. Impact of sarcopenia, BMI, and inflammatory biomarkers on survival in advanced hepatocellular carcinoma treated with anti-PD-1 antibody. Am J Clin Oncol. $2021 \mathrm{Feb}$;44(2):74-81.

96 Qayyum A, Bhosale P, Aslam R, Avritscher R, Ma J, Pagel MD, et al. Effect of sarcopenia on systemic targeted therapy response in patients with advanced hepatocellular carcinoma. Abdom Radiol. 2021 Mar;46(3):100815.

97 Ney M, Vandermeer B, van Zanten SJ, Ma MM, Gramlich L, Tandon P. Meta-analysis: oral or enteral nutritional supplementation in cirrhosis. Aliment Pharmacol Ther. 2013 Apr;37(7):672-9.

98 Maharshi S, Sharma BC, Sachdeva S, Srivastava S, Sharma P. Efficacy of nutritional therapy for patients with cirrhosis and minimal hepatic encephalopathy in a randomized trial. Clin Gastroenterol Hepatol. 2016 Mar;14(3):454-33.

99 Merli M, Berzigotti A, Zelber-Sagi S, Dasarathy S, Montagnese S, Genton L, et al. EASL clinical practice guidelines on nutrition in chronic liver disease. J Hepatol. 2019 Jan; 70(1):172-93.

100 Tsien CD, McCullough AJ, Dasarathy S. Late evening snack: exploiting a period of anabolic opportunity in cirrhosis - evening snack for cirrhotic sarcopenia. J Gastroenterol Hepatol. 2012 Mar;27(3):430-41.

101 Eslamparast T, Montano-Loza AJ, Raman M, Tandon P. Sarcopenic obesity in cirrhosis: the confluence of 2 prognostic titans. Liver Int. 2018 Oct;38(10):1706-17.

102 Marchesini G, Bianchi G, Merli M, Amodio P, Panella C, Loguercio C, et al. Nutritional supplementation with branched-chain ami- no acids in advanced cirrhosis: a doubleblind, randomized trial. Gastroenterology. 2003 Jun;124(7):1792-801.

103 Muto Y, Sato S, Watanabe A, Moriwaki H, Suzuki K, Kato A, et al. Effects of oral branched-chain amino acid granules on event-free survival in patients with liver cirrhosis. Clin Gastroenterol Hepatol. $2005 \mathrm{Jul}$; 3(7):705-13.

104 Gluud LL, Dam G, Les I, Córdoba J, Marchesini G, Borre M, et al. Branched-chain amino acids for people with hepatic encephalopathy. Cochrane Database Syst Rev. 2015;(2): CD001939. Chichester, UK: John Wiley \& Sons, Ltd. pub2.

105 Plauth M, Bernal W, Dasarathy S, Merli M, Plank LD, Schütz T, et al. ESPEN guideline on clinical nutrition in liver disease. Clin Nutr. 2019 Apr;38(2):485-521.

106 Nicastro H, Artioli GG, dos Santos Costa A, Solis MY, da Luz CR, Blachier F, et al. An overview of the therapeutic effects of leucine supplementation on skeletal muscle under atrophic conditions. Amino Acids. 2011 Feb;40(2):287-300.

107 Holeček M. Beta-hydroxy-beta-methylbutyrate supplementation and skeletal muscle in healthy and muscle-wasting conditions: HMB supplementation and muscle. J Cachexia Sarcopenia Muscle. 2017 Aug;8(4): 529-41.

108 Román E, Torrades MT, Nadal MJ, Cárdenas G, Nieto JC, Vidal S, et al. Randomized Pilot Study: effects of an exercise programme and leucine supplementation in patients with cirrhosis. Dig Dis Sci. 2014 Aug;59(8): 1966-75.

109 Deutz NEP, Safar A, Schutzler S, Memelink R, Ferrando A, Spencer H, et al. Muscle protein synthesis in cancer patients can be stimulated with a specially formulated medical food. Clin Nutr. 2011 Dec;30(6):759-68.

110 May PE, Barber A, D’Olimpio JT, Hourihane A, Abumrad NN. Reversal of cancerrelated wasting using oral supplementation with a combination of beta-hydroxy-betamethylbutyrate, arginine, and glutamine. Am J Surg. 2002 Apr;183(4):471-9.

111 Kumar A, Davuluri G, Welch N, Kim A, Gangadhariah M, Allawy A, et al. Oxidative stress mediates ethanol-induced skeletal muscle mitochondrial dysfunction and dysregulated protein synthesis and autophagy. Free Radic Biol Med. 2019 Dec; 145:284-99.

112 Malaguarnera M, Vacante M, Giordano M, Pennisi G, Bella R, Rampello L, et al. Oral acetyl-1-carnitine therapy reduces fatigue in overt hepatic encephalopathy: a randomized, double-blind, placebo-controlled study. Am J Clinical Nutr. 2011 Apr;93(4): 799-808.

113 Hiramatsu A, Aikata H, Uchikawa S, Ohya K, Kodama K, Nishida Y, et al. Levocarnitine use is associated with improvement in sarcopenia in patients with liver cirrhosis. Hepatol Commun. 2019 Mar;3(3):348-55.
114 Gramignano G, Lusso MR, Madeddu C, Massa E, Serpe R, Deiana L, et al. Efficacy of 1-carnitine administration on fatigue, nutritional status, oxidative stress, and related quality of life in 12 advanced cancer patients undergoing anticancer therapy. Nutrition. 2006 Feb;22(2):136-45

115 Remelli F, Vitali A, Zurlo A, Volpato S. Vitamin D deficiency and sarcopenia in older persons. Nutrients. 2019 Nov;11(12): 2861.

116 Ebadi M, Bhanji RA, Mazurak VC, Lytvyak E, Mason A, Czaja AJ, et al. Severe vitamin $\mathrm{D}$ deficiency is a prognostic biomarker in autoimmune hepatitis. Aliment Pharmacol Ther. 2019 Jan;49(2):173-82.

117 Okubo T, Atsukawa M, Tsubota A, Ono H, Kawano T, Yoshida Y, et al. Effect of vitamin D supplementation on skeletal muscle volume and strength in patients with decompensated liver cirrhosis undergoing branched chain amino acids supplementation: a prospective, randomized, controlled pilot trial. Nutrients. 2021 May; 13(6): 1874 .

118 Kennel KA, Drake MT. Vitamin D in the cancer patient. Curr Opin Support Palliat Care. 2013 Sep;7(3):272-7.

119 Becker C, Lord SR, Studenski SA, Warden SJ, Fielding RA, Recknor CP, et al. Myostatin antibody (LY2495655) in older weak fallers: a proof-of-concept, randomised, phase 2 trial. Lancet Diabet Endocrinol. 2015 Dec; 3(12):948-57.

120 Choi K, Jang HY, Ahn JM, Hwang SH, Chung JW, Choi YS, et al. The association of the serum levels of myostatin, follistatin, and interleukin-6 with sarcopenia, and their impacts on survival in patients with hepatocellular carcinoma. Clin Mol Hepatol. 2020 Oct;26(4):492-505.

121 Dev R, Wong A, Hui D, Bruera E. The evolving approach to management of cancer cachexia. Oncology. 2017 Jan;31(1): 23-32.

122 Sinclair M, Grossmann M, Hoermann R, Angus PW, Gow PJ. Testosterone therapy increases muscle mass in men with cirrhosis and low testosterone: a randomised controlled trial. J Hepatol. 2016 Nov;65(5):90613.

123 Yip TC, Wong GL, Chan HL, Tse Y, Liang LY, Hui VW, et al. Elevated testosterone increases risk of hepatocellular carcinoma in men with chronic hepatitis $\mathrm{B}$ and diabetes mellitus. J Gastroenterol Hepatol. 2020 Dec; 35(12):2210-9.

124 Kanda T, Yokosuka O. The androgen receptor as an emerging target in hepatocellular carcinoma. J Hepatocell Carcinoma. 2015 Jun;2:91.

125 Debette-Gratien M, Tabouret T, Antonini MT, Dalmay F, Carrier P, Legros R, et al Personalized adapted physical activity before liver transplantation: acceptability and results. Transplantation. 2015 Jan;99(1): $145-50$. 
126 Zenith L, Meena N, Ramadi A, Yavari M, Harvey A, Carbonneau M, et al. Eight weeks of exercise training increases aerobic capacity and muscle mass and reduces fatigue in patients with cirrhosis. Clin Gastroenterol Hepatol. 2014 Nov; 12(11):1920-6.e2.

127 Lønbro S, Dalgas U, Primdahl H, Johansen J, Nielsen JL, Aagaard P, et al. Progressive resistance training rebuilds lean body mass in head and neck cancer patients after radiotherapy: results from the randomized DAHANCA 25B trial. Radiother Oncol. 2013 Aug;108(2):314-9.

128 Sinclair M, Gow PJ, Grossmann M, Angus PW. Review article: sarcopenia in cirrhosis - aetiology, implications and potential therapeutic interventions. Aliment Pharmacol Ther. 2016 Apr;43(7):765-77.
129 Tandon P, Ismond KP, Riess K, Duarte-Rojo A, Al-Judaibi B, Dunn MA, et al. Exercise in cirrhosis: translating evidence and experience to practice. J Hepatol. 2018 Nov;69(5): 1164-77.

130 Duarte-Rojo A, Ruiz-Margáin A, MontañoLoza AJ, Macías-Rodríguez RU, Ferrando A, Kim WR. Exercise and physical activity for patients with end-stage liver disease: improving functional status and sarcopenia while on the transplant waiting list. Liver Transpl. 2018 Jan;24(1):122-39.

131 Aamann L, Dam G, Borre M, DrljevicNielsen A, Overgaard K, Andersen H, et al. Resistance training increases muscle strength and muscle size in patients with liver cirrhosis. Clin Gastroenterol Hepatol. 2020 May;18(5):1179-87.e6.
132 Koya S, Kawaguchi T, Hashida R, Goto E, Matsuse H, Saito H, et al. Effects of in-hospital exercise on liver function, physical ability, and muscle mass during treatment of hepatoma in patients with chronic liver disease: in-hospital exercise during hepatoma therapy. Hepatol Res. 2017 Mar;47(3):E2234 .

133 Koya S, Kawaguchi T, Hashida R, Hirota K, Bekki M, Goto E, et al. Effects of in-hospital exercise on sarcopenia in hepatoma patients who underwent transcatheter arterial chemoembolization. J Gastroenterol Hepatol. 2019;34:580-8

134 Le Cornu KA, McKiernan FJ, Kapadia SA, Neuberger JM. A prospective randomized study of preoperative nutritional supplementation in patients awaiting elective orthotopic liver transplantation. Transplantation. 2000 Apr;69(7):1364-9. 